\title{
Correction to: Environmental risk assessment of platinum cytotoxic drugs: a focus on toxicity characterization of hospital effluents
}

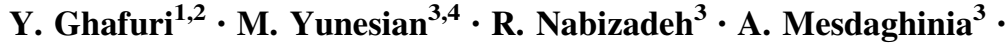

M. H. Dehghani ${ }^{3} \cdot$ M. Alimohammadi ${ }^{1,5}$

Published online: 3 October 2017

(C) Islamic Azad University (IAU) 2017

\section{Correction to: Int. J. Environ. Sci. Technol. \\ DOI 10.1007/s13762-017-1517-6}

The original version of this article unfortunately contained a mistake. The spelling of the Y. Ghafuri's name was incorrect. The corrected name is given above.

The online version of the original article can be found under doi:10.1007/s13762-017-1517-6.

\section{Alimohammadi}

m_alimohammadi@tums.ac.ir

1 Department of Environmental Health Engineering, School of Public Health, International Campus, Tehran University of Medical Sciences (IC-TUMS), Tehran, Iran

2 Environmental Research Center, Qom University of Medical Science, Qom, Iran

3 Department of Environmental Health Engineering, School of Public Health, Tehran University of Medical Sciences, Tehran, Iran

4 Center for Air Pollution Research, Institute for Environmental Research, Tehran University of Medical Science, Tehran, Iran

5 Center for Water Quality Research, Institute for Environmental Research, Tehran University of Medical Science, Tehran, Iran 